\title{
ESTONIAN AND FINNISH GRADUATING SENIORS' OPINIONS AND MOTIVATION ABOUT PHYSICAL EDUCATION
}

\author{
K. Ahlbäck, A. Koka, T. Janson \\ Institute of Sport Pedagogy and \\ Coaching, University of Tartu, Tartu, Estonia
}

\begin{abstract}
This study investigated the general feelings and opinions about their health, school, leisure time physical activity and physical education among senior graduating students in Estonia and Finnish. The results showed that Estonian and Finnish youth had similar opinions about their health and the similar patterns in leisure time physical activity.

Many of the Finnish and Estonian graduating senior reported that there is something that bothers in PE classes (PE classes are boring, condition, evaluation system). Finnish and Estonians students reported that evaluation is based on too much performing of general standards although evaluation should measure more individual development and how individual pushes during the PE classes. Most of the Estonian students reported that conditions during and especially after PE classes needed improvements. The study demonstrated that Finnish boys were more interested in having more PE in schools than Estonian boys. However most of the Estonian graduating students reported that there should be more optional PE lessons for choosing in schools.

Additionally, in terms of motivation in physical education, the study revealed that the external type of motivation among Estonian girls was significantly higher compared to Finnish girls.
\end{abstract}

Key words: health, leisure time physical activity, intrinsic and extrinsic motivation, physical education. 


\section{INTRODUCTION}

Physical education (PE) is being viewed as an important means in promoting health and wellness that may, in turn, influence students to lead physically active lifestyles. Attitudes toward physical activity and perceptions about physical education classes are important to understand as they can influence an individual's decision to begin or to continue participation in an activity [1]. A thorough understanding about students' attitude towards physical activity will give an impact on the effectiveness of teachers and the planning of programs that cater for student needs in order to ensure the achievement of predetermined objectives and aims [13]. Furthermore, research in this area identifies curriculum content, classroom environment, and teacher behavior as the primary determinants of negative and positive attitudes toward physical education [4].

Children and youth must learn healthful living habits while in school because many will not attend college or be able to afford fitness club memberships or expensive exercise equipments. Through participation in sports, students can develop positive personal traits, such as self-confidence and discipline, and social skills, such as teamwork and sportsmanship [11].

There are several problems and open questions when discussing about the connection between the physical activity and the school physical education. What is clear is that present policies and approaches in physical education curricula do not seem to be having a positive impact with regard to facilitating the adoption of an active lifestyle. Because of this, it is important to explore ways to use physical education to increase physical activity and promote healthy lifestyles [5].

Research's has consistently demonstrated that enjoyment represents a key factor underlying the motivation for children and youth to maintain positive engagement in both physical activity and PE. In relation to school physical education, enjoyment represents a direct and tangible influence on students' participatory behavior, providing immediate reward for being physically active. It is important, therefore, for researchers to acquire a clearer understanding of the motivational mechanisms that underlie the positive or negative affective outcomes of PE, such as enjoyment or anxiety [17].

The purpose of this study was to investigate general feelings and opinions about health, leisure time physical activity and physical 
education, as well as motivation in physical education among senior graduating students in Estonia and Finnish.

Research is needed because this kind of knowledge could be useful for making PE classes more attractive and effective for school-aged Estonian and Finnish youth.

\section{METHODS AND PROCEDURES}

\section{Participants and procedures}

Participants were 269 graduating seniors (140 Estonians and 129 Finnish) from 8 different high schools in Tartu (Estonia) and Tampere, Nokia (Finland) (Table 1). Permission to carry out the questionnaire in each school was obtained from the administration, headmaster and the physical education teachers. The anonymous questionnaire was administered in the classrooms. The purpose of the study was explained and the instructions were given for completing the questionnaire. It was emphasized that the questionnaire was designed to measure students' general feelings and opinions about PE classes.

Table 1.The anthropometrics results of Estonian $(\mathrm{n}=140)$ and Finnish $(\mathrm{n}=123)$ graduating seniors.

\begin{tabular}{|l|c|c|c|c|c|}
\hline Group & n & \multicolumn{2}{|c|}{ Height (cm) } & \multicolumn{2}{c|}{ Weight (kg) } \\
\hline & & mean & SD & mean & SD \\
\hline Estonian boys & 79 & 183.2 & 5.5 & 75.6 & 13.4 \\
\hline Finnish boys & 70 & 179.5 & 6.3 & 73.5 & 9.8 \\
\hline Estonian girls & 61 & 169.3 & 5.4 & 59.0 & 7.3 \\
\hline Finnish girls & 53 & 166.6 & 5.1 & 58.0 & 10.2 \\
\hline
\end{tabular}

\section{MEASURES}

The questionnaire was divided into two parts. The first part of the questionnaire, compiled by the authors of this study, examined students' general feelings and opinions about their health, studies in school, leisure time physical activity and physical education. Second part of the questionnaire examined students' motivation in physical education. The Sport Motivation Scale (SMS), developed by Pelletier 
et al., [14], which has been adapted to physical education and translated into Estonian by Hein and colleagues [8] and into Finnish by Jaakkola [9], was used. The SMS consisted of 28 items examining participants' motivation with three types of intrinsic motivation (intrinsic motivation to know, to accomplish, and to experience), three types of extrinsic motivation (identified, introjected, and external regulation) and amotivation. Since these three types of intrinsic motivation have shown to be strongly correlated [10], the averaged scores of three types of intrinsic motivation were used to characterize a global intrinsic motivation variable. Also, averaged scores of three types of extrinsic motivation were used in this study to characterize a global extrinsic motivation variable. Students responded to the items on a 7 -point scale ranging from $1=$ totally agree to $7=$ totally disagree.

\section{Statistical analysis}

The data was analyzed using statistical package of SPSS 17.0. The cross tabulation analysis was used to examine the distribution of responses to the items asking students' opinions about their health, school, leisure time physical activity, and physical education. The chisquare statistics was utilized to determine whether the differences in distribution of responses were statistically significant. In order to determine differences in students' motivation in physical education, independent samples t-test was used.

In this study the focus was on determining the possible national differences between Estonian and Finnish senior graduating students. Specifically differences between Estonian and Finnish male senior graduating students, as well as Estonian and Finnish female senior graduating students were determined. Statistical significance was set at $\mathrm{p}<0.05$.

\section{RESULTS}

\section{Graduating seniors' opinions about their health and physical activity}

Results revealed that $35.4 \%$ of Estonian boys and $33.8 \%$ of Finnish boys valued their health as very good. $53.2 \%$ of Estonian boys and $56.3 \%$ of Finnish boys valued their health as good. $11.4 \%$ of Estonian 
boys and $9.9 \%$ of Finnish boys valued their health as moderate. None of Estonian or Finnish boys valued their health as poor. Differences between Estonian and Finnish boys were not statistically significant: $\chi^{2}(2, \mathrm{n}=150)=0.180, \mathrm{p}>0.05$.

As for girls, results revealed that $23.0 \%$ of Estonian girls and $8.6 \%$ of Finnish girls valued their health as very good. $60.7 \%$ of Estonian girls and $77.6 \%$ of Finnish girls valued their health as good. $16.4 \%$ of Estonian girls and $13.8 \%$ of Finnish girls valued their health as moderate. None of Estonian or Finnish girls valued their health as poor. Differences between Estonian and Finnish girls were not statistically significant: $\chi^{2}(2, \mathrm{n}=119)=5.194, \mathrm{p}>0.05$.

In terms of physical fitness, results revealed that $16.5 \%$ of Estonian boys and $19.7 \%$ of Finnish boys valued their physical fitness as very good. $43.0 \%$ of Estonian boys and $43.7 \%$ of Finnish boys valued their physical fitness as good. $38.0 \%$ of Estonian boys and $29.6 \%$ of Finnish boys valued their physical fitness as moderate and $2.5 \%$ of Estonian boys and $7.0 \%$ of Finnish boys valued their physical fitness as poor. Chi-square test revealed that the percentage of these answers were not statistically significantly different among Estonian and Finnish boys: $\chi^{2}(3, \mathrm{n}=150)=2.630, \mathrm{p}>0.05$.

As for girls, results revealed that $9.8 \%$ of Estonians and $5.2 \%$ of Finnish students valued their physical fitness as very good. $63.9 \%$ of Estonian girls and $50.0 \%$ of Finnish girls valued their physical fitness as good. $23.0 \%$ of Estonian girls and $41.4 \%$ of Finnish girls valued their physical fitness as moderate and 3.3\% of Estonian girls and 3.4\% of Finnish girls valued their physical fitness as poor. The percentages of these answers were not statistically significantly different among Estonian and Finnish girls: $\chi^{2}(3, n=119)=5.030, p>0.05$.

In terms of physical activity, results revealed that $17.7 \%$ of Estonian boys and $15.7 \%$ of Finnish boys were physically active more than four times a week. $21.5 \%$ of Estonian boys and $31.4 \%$ of Finnish boys were physically active three to four times a week. $39.2 \%$ of Estonian boys and $24.3 \%$ of Finnish boys were physically active one or two time a week. $16.5 \%$ of Estonian boys and $24.3 \%$ of Finnish boys were physically active less than once a week. $5.1 \%$ of Estonian boys and $4.3 \%$ of Finnish boys reported that they are not physically active. Differences between the Estonian and Finnish boys were not statistically significant: $\chi^{2}(4, \mathrm{n}=149)=5.236, \mathrm{p}>0.05$.

For girls the results revealed that, 9.8\% of Estonian girls and $19.0 \%$ of Finnish girls were physically active more than four times a 
week. $24.6 \%$ of Estonian girls and $24.1 \%$ of Finnish girls were physically active three to four times a week. $32.8 \%$ of Estonian girls and $34.5 \%$ of Finnish girls were physically active one or two times a week. $27.9 \%$ of Estonian girls and $19.0 \%$ of Finnish girls were physically active less than once a week. $4.9 \%$ of Estonian girls and $3.4 \%$ of Finnish girls reported that they are not physically active. Differences between the Estonian and Finnish girls were not statistically significant: $\chi^{2}(4, \mathrm{n}=149)=2.917, \mathrm{p}>0.05$.

Next the students were asked to indicate how many hours per week they are physically active on leisure time that causes sweating. Results showed that $21.5 \%$ of Estonian boys and $18.8 \%$ of Finnish boys were physically active more than five hours per week. $8.9 \%$ of Estonian boys and $13.0 \%$ of Finnish boys were physically active four or five hours per week. $22.8 \%$ of Estonian boys and $21.7 \%$ of Finnish boys were physically active three to four hours per week. $38.0 \%$ of Estonian boys and $29.0 \%$ of Finnish boys were physically active approximately one hour per week. $8.9 \%$ of Estonian boys and $17.4 \%$ of Finnish boys reported that they are not physically active at all. Differences between the Estonian and Finnish boys were not statistically significant: $\chi^{2}(4, \mathrm{n}=148)=3.713, \mathrm{p}>0.05$.

As for girls, $11.5 \%$ of Estonian girls and $12.1 \%$ of Finnish girls were physically active on leisure time that causes sweating more than five hours per week. $6.6 \%$ of Estonian girls and 3.4\% of Finnish girls were physically active four to five hours per week. $23.0 \%$ of Estonian girls and $24.1 \%$ of Finnish girls were physically active three or four hours a week. $36.1 \%$ of Estonian girls and $41.4 \%$ of Finnish girls were physically active approximately one hour per week. $23.0 \%$ of Estonian girls and $19.0 \%$ of Finnish girls reported that they are not physically active at all. Differences between the Estonian and Finnish girls were not statistically significant: $\chi^{2}(4, \mathrm{n}=119)=1.039, \mathrm{p}>0.05$.

Students were also asked to indicate where they exercise in their leisure time. Results indicated that $35.4 \%$ of Estonian boys and $37.7 \%$ of Estonian girls reported that training in sport clubs is the most popular way of doing sports after school. $38.6 \%$ of Finnish boys and $51.7 \%$ of Finnish girls were training most often with the friends without coaching. Differences between the Estonian and the Finnish boys were not statistically significant: $\chi^{2}(4, n=148)=3.713, p>0.05$. However Chi-square test revealed that the percentage of answers was statistically significant between Estonian and Finnish girls: $\chi^{2}$ (5, $\mathrm{n}=119)=11.381, \mathrm{p}<0.05$. 


\section{Graduating seniors' opinions about physical education}

Students were asked to indicate whether they like PE lessons. Results revealed that, $84.8 \%$ of Estonian boys and $84.3 \%$ of Finnish boys liked PE lessons $\left(\chi^{2}(1, \mathrm{n}=149)=0.008, \mathrm{p}>0.05\right)$. For girls, $75.4 \%$ of Estonian girls and $71.9 \%$ of Finnish girls liked PE lessons $\left(\chi^{2}(1, \mathrm{n}=\right.$ $18)=0.182, \mathrm{p}>0.05)$.

Students were next asked to indicate whether they consider PE lessons as interesting. Results revealed that $75.9 \%$ of Estonian boys and $81.4 \%$ of Finnish boys rated PE lessons as interesting. $\left(\chi^{2}(1\right.$, $\mathrm{n}=149)=0.661, \mathrm{p}>0.05$ ). For girls, $63.9 \%$ of Estonian girls and $63.8 \%$ of Finnish girls rated PE lessons as interesting $\left(\chi^{2}(1, n=119)=0.000\right.$, $\mathrm{p}>0.05)$.

When asked about the importance of PE, 83.3\% of Estonian boys and $80.3 \%$ of Finnish boys reported PE lessons are important $\left(\chi^{2}(1\right.$, $\mathrm{n}=149)=0.233, \mathrm{p}>0.05$ ). Answers from girls revealed that $80.3 \%$ of Estonian girls and $85.7 \%$ of Finnish girls though that PE lessons are important $\left(\chi^{2}(1, \mathrm{n}=117)=0.598, \mathrm{p}>0.05\right)$.

When asked whether the students enjoy PE lessons results revealed that $75.6 \%$ of Estonian boys and $87.1 \%$ of Finnish boys enjoyed the PE classes $\left(\chi^{2}(1, n=148)=3.182, p>0.05\right)$. For girls, the results revealed that $70.5 \%$ of Estonian girls and $77.2 \%$ of Finnish girls enjoyed the PE classes $\left(\chi^{2}(1, n=118)=0.683, p>0.05\right)$.

\section{Graduating seniors' opinions about relationships in physical education}

When asked about the students' relationship with their PE teacher the results indicated that $49.4 \%$ of Estonian boys and $57.1 \%$ of Finnish boys having very good relationship with the PE teacher. $44.3 \%$ of Estonian boys and about $38.6 \%$ of Finnish boys reported that they get well along with the PE teacher. Only $2.9 \%$ of Finnish boys and none of Estonian boys reported that they don't get along with the PE teacher $\left(\chi^{2}(3, n=149)=7.362, p>0.05\right)$. As for girls, $57.7 \%$ of Estonian girls and $24.1 \%$ of Finnish girls reported that they get very well along with the PE teacher. $29.5 \%$ of Estonian girls but $72.4 \%$ of Finnish girls reported that they get well along with the PE teacher. $4.9 \%$ of Estonian girls and none of Finnish girls reported that they don't get along with the PE teacher. Chi-square test revealed that the percentage of these answers were statistically different among Estonian and Finnish girls: $\chi^{2}(3, n=119)=22.872, p<0.05$. 
The results revealed that $53.2 \%$ of Estonian boys and $52.9 \%$ of Finnish boys reported that they get very well along with the classmates in PE. $46.8 \%$ of Estonian boys and $38.6 \%$ of Finnish boys reported that they get well along with the classmates in PE. Only $2.9 \%$ of Finnish boys and none of Estonian boys reported that they don't get along with the classmates in PE $\left(\chi^{2}(3, n=149)=7.362, p>0.05\right)$. As for girls, $44.3 \%$ of Estonian girls and $25.9 \%$ of Finnish girls reported that they get very well along with the classmates in PE. 52.5\% of Estonian girls and $69.0 \%$ of Finnish girls reported that they get well along with the classmates in PE. 3.3\% of Estonian girls and 5.2\% of Finnish girls reported that they don't get along with the classmates in $\operatorname{PE~}\left(\chi^{2}(2\right.$, $\mathrm{n}=119)=4.445, \mathrm{p}>0.05)$.

\section{Graduating seniors' opinions about evaluation system, provision, and conditions of physical education}

When asked from Estonian and the Finnish graduating seniors if there was anything that bothers in the PE lessons, $54.4 \%$ of Estonian boys and $88.6 \%$ of Finnish boys answered yes. Differences between the Estonian and Finnish boys were statistically significant: $\chi^{2}(1$, $\mathrm{n}=149)=20.788, \mathrm{p}<0.05$. Similarly, $49.2 \%$ of Estonian girls and $82.8 \%$ of Finnish girls reported that there is something that bothers in the PE. Differences between the girls were statistically different: $\chi^{2}(1$, $\mathrm{n}=119)=14,844, \mathrm{p}<0.05$. The notion that "PE classes are boring" was one of the main reasons why Estonian and Finnish boys and girls reported that there is something that bothers in the PE classes (Figure 1).

The results were following when graduating seniors were asked the question Do you like the evaluation system in PE. 72.2\% of Estonian boys and $91.5 \%$ of Finnish boys answered yes $\left(\chi^{2}(1, n=150)=9.267\right.$, $\mathrm{p}<0.05$ ). For girls, $59.0 \%$ of Estonian and $83.6 \%$ of Finnish girls answered yes $\left(\chi^{2}(1, \mathrm{n}=116)=8.461, \mathrm{p}<0.05\right)$. Estonian and Finnish boys and girls reported that evaluation is based on too much on performing on general standards although evaluation should measure more individual development and how does the individual push during the PE classes. 


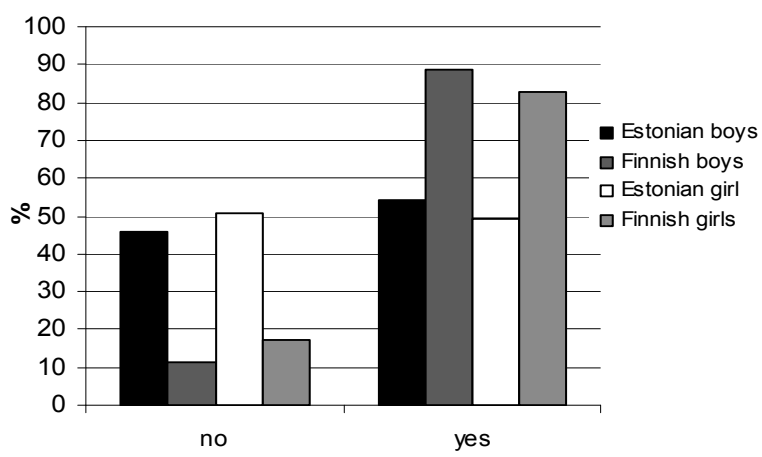

Figure 1. Students' opinion when asked if there was anything that bothers in the PE lessons.

The results of study revealed that $43.6 \%$ of Estonian boys and $60.6 \%$ of Finnish boys reported that there should be more PE lessons in schools $\left(\chi^{2}(1, \mathrm{n}=149)=4.288, \mathrm{p}<0.05\right)$. From girls, $22.9 \%$ of Estonians and $44.6 \%$ of Finnish reported that there should be more PE lessons in schools $\left(\chi^{2}(1, \mathrm{n}=117)=2.877, \mathrm{p}>0.05\right)$.

When asked about the conditions to carry out the PE lessons, 7.9\% of Estonians and $16.4 \%$ Finnish reported that the conditions are very good. $40.7 \%$ of Estonians and $60.2 \%$ of Finnish rated PE conditions as good. $39.3 \%$ of Estonians and $18.8 \%$ of Finnish rated PE conditions as moderate and $12.1 \%$ of Estonian and $4.7 \%$ of Finnish as poor. Chisquare test revealed that the percentage of these answers were statistically different between Estonian and Finnish students: $\chi^{2}(3$, $\mathrm{n}=268)=23.044, \mathrm{p}<0.05$. Results showed also the differences between the Estonian and Finnish boys and girls (Figure 2). 


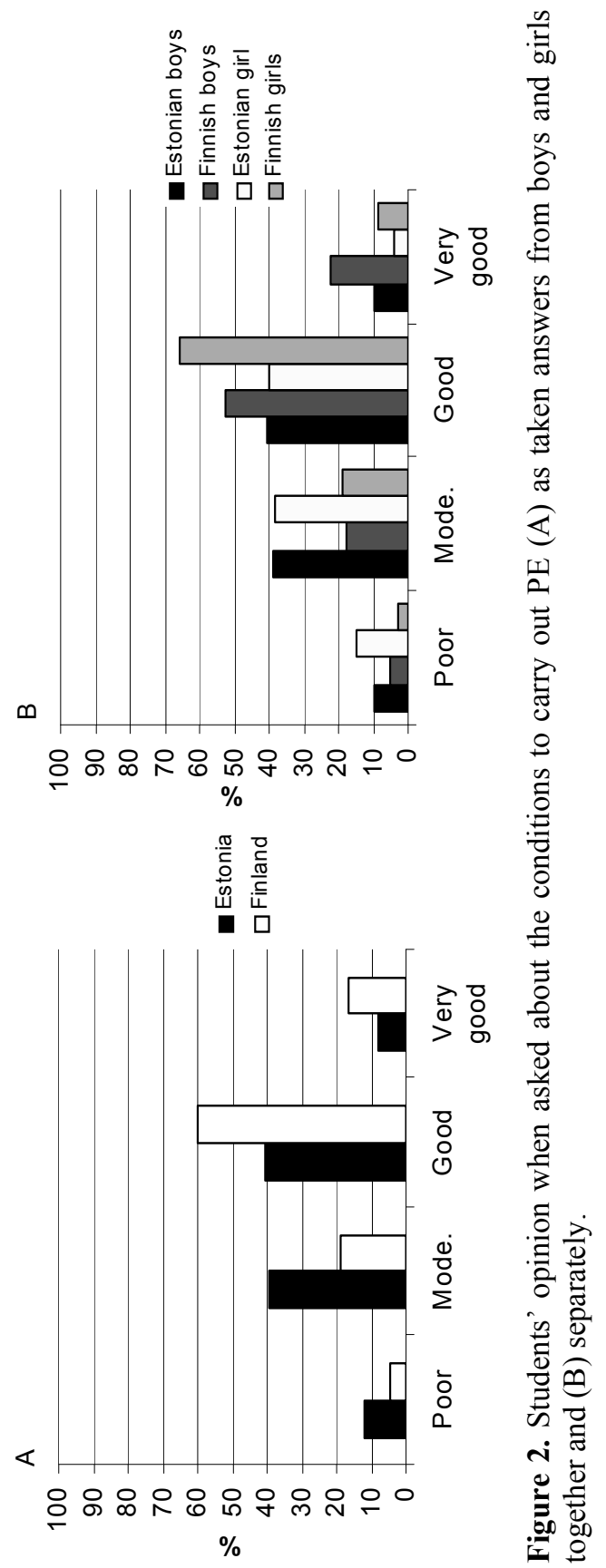


The results were following when asked about the sanitary conditions after physical education classes. The sanitary conditions rated as very good $14.4 \%$ of Estonians and $14.8 \%$ of Finnish, as good rated $18.0 \%$ of Estonians and $50.0 \%$ of Finnish, as moderate rated $29.5 \%$ of Estonians and $31.3 \%$ of Finnish and as poor rated $38.1 \%$ of Estonians and $3.9 \%$ of Finnish (Figure 3). The answers were statistically different between Estonian and Finnish students: $\chi^{2}(3, n=267)=$ $56.495, \mathrm{p}<0.05$. Estonian student's reported that there were no enough showers for students or rooms were narrow, the condition of the locker room or the shower room was bad, locker rooms and shower rooms were dirty or smelly and there were frequently no warm water coming from the showers.

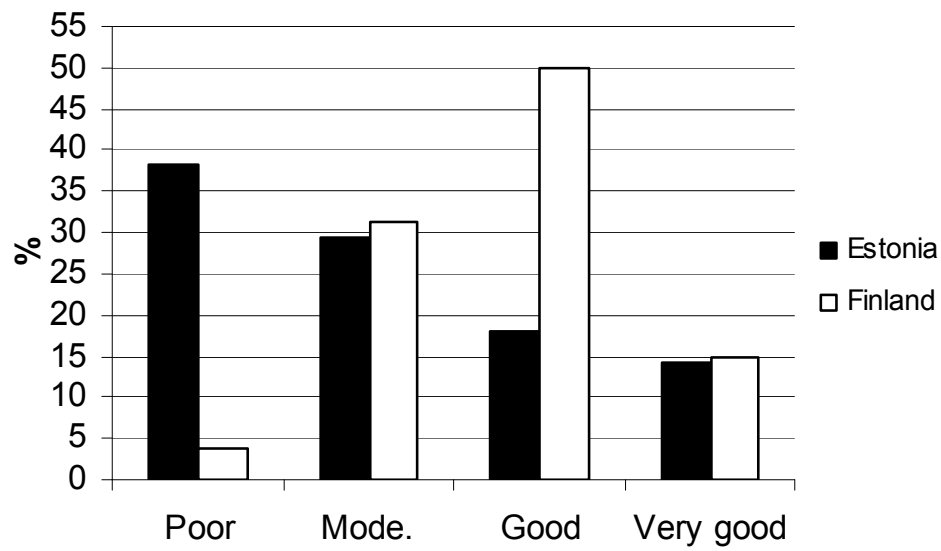

Figure 3. Students' opinion when asked about the sanitary conditions after PE lessons.

\section{Motivation in physical education}

An independent-samples t-test was conducted to compare Estonians and Finnish graduating seniors amotivation, intrinsic motivation and external motivation. There was no significant differences in amotivation between Estonian $(\mathrm{M}=2.5 \pm 1.1)$ and Finnish boys $($ mean $=2.3, \mathrm{SD}=1.3)[\mathrm{t}(137)=0.96, \mathrm{p}=0.34]$; in intrinsic motivation between Estonian (mean=4.3, $\mathrm{SD}=1.3$ ) and Finnish (mean=4.7, $\mathrm{SD}=1.3$ ) boys $[\mathrm{t}(137)=-1.89, \mathrm{p}=0.06]$; nor in external motivation 
between the Estonian (mean=3.8, $\mathrm{SD}=1.3$ ) and Finnish (mean=4.2, $\mathrm{SD}=1.3$ ) boys: $[\mathrm{t}(137)=-1.58, \mathrm{p}=0.12]$.

The motivational responses towards physical education among Estonian and Finnish girls revealed that there were no significant differences in amotivation between Estonian (mean=2.6, $\mathrm{SD}=1.3$ ) and Finnish (mean=2.5, SD=1.1) girls $[\mathrm{t}(115)=0.3, \mathrm{p}=0.76]$; nor in intrinsic motivation between Estonian (mean=4.4, $\mathrm{SD}=1.3$ ) and Finnish (mean=4.2, $\mathrm{SD}=1.1)$ girls $[\mathrm{t}(111)=1.04, \mathrm{p}=0.3]$. There was, however, a significant difference in external motivation between the Estonian (mean=4.0, $\mathrm{SD}=1.1$ ) and Finnish (mean=3.5, $\mathrm{SD}=1.0)$ girls $[\mathrm{t}(115)=2.39, \mathrm{p}=0.02]$. The external motivation of Estonian girls was significantly higher compared to Finnish girls.

\section{DISCUSSION}

\section{Finnish and Estonian graduating seniors' opinions about their health and leisure time physical activity}

The Estonian and the Finnish girls rated their health as moderate and as good. However, Estonian and Finnish boys rated their health as very good. Fair or poor self-rated health tends to be more common among older children and girls [16]. Although most of the Finnish girls did not rate their health as very good, they reported the highest percentage when the frequencies of leisure time physical activity were over four times a week. The minimum recommendations of daily PA for 18-year-olds are at least one hour [6], so results revealed that only a small group of Estonian and Finnish graduating seniors are reaching the limit of being physically active at least one hour per day. As Bugge et al. [2] reported, many children do not meet current recommendations of physical activity and that may become a threat to the health of the up-coming adult population. Findings revealed that the most popular way of making sports among Estonian graduating seniors were training in sport clubs where as in Finnish graduating seniors the most popular way of making sports was with friends and without coaching. However, the study revealed that there were no significant differences between the Estonian and Finnish pupils in health and leisure time physical activity. 


\section{Finnish and Estonian graduating seniors' opinions about physical education}

Findings revealed that more than half of the Estonian and Finnish boys and girls reported that PE lessons are important. Bibik et al., [1] studied High school students' attitudes toward their physical education programs in the state of Delaware and descriptive analyses revealed that $43.5 \%$ of both high school boys and girls rated physical activity to be important in their high school studies. Compared findings abovementioned Estonian and Finnish graduating seniors' opinions were more positive about importance of PE. Estonian and Finnish students' opinions about enjoyment and interest in PE were also very high. Bibik et al., [1] reported that, the students' enjoyment of physical education is significantly correlated with attribution of team sports (such as basketball, baseball, floor hockey and volleyball), fitness activities (aerobic dance, weight training, bicycling), individual games (tennis, badminton, track, pickle ball), and self-defense (wrestling, karate, judo) in the physical education curriculum. The positive attitude and perception of students towards physical activities are the main elements in evaluating the success of a particular Physical Education curriculum [13]. It is possible that because of the high level of enjoyment and interest toward PE that both Estonian and Finnish students reported in this study, their consider PE also as important.

When it was asked about the students' relationship with their PE teacher and classmates, findings revealed that Estonian boys opinions were a bit positive compared to Finnish boys. As for girls, Estonian girls reported a very good relationship with the PE teacher compared to Finnish girls. Opinions about the relationships to classmates were more equal between the Estonian and Finnish girls but Estonian girls opinions were however little bit more positive. Bibik et al. [1] wrote that the students in the latter study appeared to engage in more active behavior in physical education classes when they received interest and positive reinforcement from their peers. Finding in the present study is not similar, when referring to the Bibik et al. [1] study, although Estonian girls' relationships toward PE teacher and classmates are more positive, there are no significantly different in the opinions about PE classes between the Estonian and the Finnish girls.

Compared to the Estonian boys and girls most of the Finnish boys and girls reported that there is something that bothers in PE classes. Many of Estonian and Finnish students reported that PE classes are 
boring because they are doing all the time the same sports or exercise workouts. Considering that one of the important goals is to foster students' interest in physical education, it is crucial for physical educators to present learning activities in interesting, novel, and meaningful ways, and create a safe and caring learning environment to enhance students' situational interest in physical education [7]. Findings are similar to the findings of Bibik et al., [1], who revealed that approximately $21 \%$ of students responded that physical educators should teach more sports or games while approximately $13 \%$ indicated physical educators should teach more skills and strategies and $7.3 \%$ responded that students should learn more about fitness. Only $2.5 \%$ of the students responded that there was nothing they liked about physical education. Findings revealed that compared to Estonian graduating seniors, many of the Finnish graduating senior reported that they don't like the evaluation system in PE. Finnish boys and girls but also Estonian boys and girls reported that evaluation is based too much on performing of general standards although evaluation should measure more individual development and how individual pushes during the PE classes.

Compared to Estonian students, Finnish students' opinions were more positive when asked about should there be more PE lessons in schools. Estonian girls had the most negative opinions about extra PE classes. However, findings revealed that most of the Estonian girls were ready to have more optional PE lessons for choosing in schools. Also Estonian boys had positive opinions for having more optional PE lessons. Reason why Estonian boys and girls have so positive feelings about having more optional PE lessons for choosing in school is probably, because High Schools in Finland it is already possible to choose more PE classes.

One of the strongest findings indicated that there was a significant difference between the Estonian and Finnish graduating seniors when asking about the conditions to carry out the PE lessons and the sanitary conditions after PE lessons. Estonian student reported conditions to carry out PE lessons as moderate and as good. Most of the Finnish student reported conditions as good. Most of the Estonian students reported sanitary conditions as poor or as moderate. Finnish students reported the sanitary conditions as good. Comfort in the locker room may have a significant impact on their enjoyment of physical education with those feeling the most uncomfortable also enjoying physical education less [1]. Research in this area identifies 
curriculum content, classroom environment, and teacher behavior as the primary determinants of negative and positive attitudes toward physical education [4].

\section{Finnish and Estonian graduating seniors' motivation in physical education}

The study revealed that there were no significant differences in amotivation, intrinsic or extrinsic motivation between Estonian and Finnish boys. The motivational responses towards physical education among Estonian and Finnish girls revealed that there were no significant differences in amotivation or in intrinsic motivation between Estonian and Finnish girls. The study revealed however a significant difference in external motivation between the Estonian and Finnish girls. The external motivation of Estonian girls was significantly higher compared to Finnish girls. There are several reasons to external motivation. In this study it revealed that the one of the main reasons for higher external motivation might be because of poor to moderate conditions of sanitary and classrooms. As mentioned before findings revealed that Estonian girls had very good relationships to PE teachers and classmates. Therefore the reasons for the Estonian girls high extrinsic motivation might be that they avoid confrontation from the PE teachers or they feel that they should participates in PE because of that is what "good students" do. PE must provide an enjoyable experience such that students do not feel that they are taking part in $\mathrm{PE}$ because of external rules or feeling of guilt [15].

The results in the cross-cultural study by Caune and Hein [3] revealed that the comparison of the types of motivation showed that Estonian children evaluated all motivation types higher than Latvian children. As mentioned, results in the present study revealed that there are no significant differences about the types of motivation between Estonians and Finnish students compared to Estonian and Latvian students.

Large epidemiological studies in the United States, the Netherlands, and Finland indicate that the largest decrease in physical activity levels occurs during early adolescence. This trend parallels age-related declines in intrinsic motivation and other adaptive indices of motivation in compulsory school PE classes. Such decreases are problematic, given that positive experiences in school PE are related to physical activity participation during leisure time [12]. 


\section{REFERENCES}

1. Bibik J. M., Goodwin S. C., Omega-Smith E. M. (2007) High school students' attitudes toward physical education in Delaware. Phys. Educat. 64: 192-204

2. Bugge A., Hermansen B., Froberg K., Andersen L.B. (2009) The CoSCIS. (Copenhagen School Child Intervention Study). $25^{\text {th }}$ International Symposium of Pediatric Work Physiology: Physical activity and Exercise for disabled and Healthy children. Paris, September $29^{\text {th }}-$ October $3^{\text {rd }}, 2009$.

3. Caune A., Hein V. (2011) Differences of the constructs related to motivation in physical education among Latvian and Estonian schoolchildren. In: Acta Kinesiologiae Universitatis Tartuensis. Fourth Baltic Conference in Exercise and Sport Sciences. April 79.2011, Jürimäe T., Pääsuke M., Jürimäe J. (eds). 16(suppl): 32.

4. Constantinou P., Manson M., Silverman S. (2009) Female Students' perceptions about gender-role stereotypes and their influence on attitude toward physical education. Phys.1 Educat. 66: 85-96

5. Daigle K., Hebert E. P. (2005) Development of an instrument to assess student attitudes toward physical education and physical activity intentions. RQES 76: A51

6. Finnish Ministry of Education. (2008)

Koulu_PDF/080129Liikuntasuosituskirja (kevyt)

7. Gao Z., Newton M. (2009) Examining the mediating role of strategy use on students' motivation and persistence/effort in physical education. J.Sport Behav. 278-297

8. Hein V., Pihu M., Koka A. (2004) Intention to be physically active after school graduation and its relationship to three types of intrinsic motivation. Eur. Phys. Educ. Rev. 10: 5-19

9. Jaakkola T. (2002) Changes in students' exercise motivation, goal orientation, and sport competence as a result of modifications in school physical education teaching practices. Research Reports on Sport and Health 131. Doctoral thesis. Jyväskylä: LIKES-Research Center

10. Koka A., Hein V. (2005) The effect of perceived teacher feedback on intrinsic motivation in physical education. Int. J.Sport Psychol. 36: 91-106

11. Lumpkins A. (2008) Introduction to physical education, exercise science, and sport studies. 7 ed. Mc Graw Hill. 28-342

12. Ntoumanis N., Standage M. (2009) Motivation in physical education classes: A self-determination theory perspective. Theor. Res. Educ. 7: 194 
13. Omar-Fauzee M.F., Jamalis M., Yusof A., Zarina M., Dev R., Dev O., Peddle M.Y., Norazemi A.G., Junaidi A.R., Dewi A.M., Latif R.A., Johar M., Nasaruddin M.N. (2009). College students perception on physical education classes during their high school days. Eur. J. Soc. Sci. 7: 4

14. Pelletier L.G., Fortier M.S., Vallerand R.J., Tuson K.M., Brie're N.M., Blais M.R. (1995) Toward a new measure of intrinsic motivation, extrinsic motivation, and amotivation in sports: The SMS (Sport Motivation Scale). J. Sport Exerc. Psychol. 17: 35-53

15. Wang C.K.J., Liu W.C. (2007) Promoting enjoyment in girls' physical education: The impact of goals, beliefs, and self-determination. Eur. Phys. Educ. Rev. 13: 145-164

16. WHO, HBSC 2005/2006. (2007) (Health Behavior in School-aged Children). International report from 2005/2006 survey

17. Yli-Piipari S., Watt A., Jaakkola T., Liukkonen J., Nurmi J.E. (2009) Relationships between physical education students' motivational profiles, enjoyment, state anxiety, and self-reported physical activity. J. Sports Sci. Med. 8: 327-336

\section{Correspondence to:}

Tamara Janson

Faculty of Exercise and Sport Sciences

University of Tartu

5 Jakobi Street

51014 Tartu

Estonia

E-mail: tamara.janson@ut.ee 